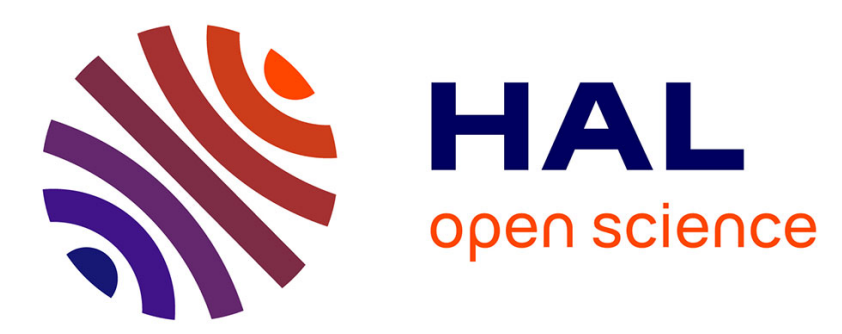

\title{
Experimental determination of GFRC tensile parameters from three-point bending tests using an analytical damage model
}

Marwa Loukil, Wiem Ben Hassine, Oualid Limam, Panagiotis Kotronis

\section{- To cite this version:}

Marwa Loukil, Wiem Ben Hassine, Oualid Limam, Panagiotis Kotronis. Experimental determination of GFRC tensile parameters from three-point bending tests using an analytical damage model. Construction and Building Materials, 2019, 223, pp.477-490. 10.1016/j.conbuildmat.2019.07.005 . hal-02178449

\author{
HAL Id: hal-02178449 \\ https://hal.science/hal-02178449
}

Submitted on 21 Oct 2019

HAL is a multi-disciplinary open access archive for the deposit and dissemination of scientific research documents, whether they are published or not. The documents may come from teaching and research institutions in France or abroad, or from public or private research centers.
L'archive ouverte pluridisciplinaire $\mathbf{H A L}$, est destinée au dépôt et à la diffusion de documents scientifiques de niveau recherche, publiés ou non, émanant des établissements d'enseignement et de recherche français ou étrangers, des laboratoires publics ou privés. 


\title{
Experimental determination of GFRC tensile parameters from three-point bending tests using an analytical damage model
}

\author{
Marwa Loukil $^{\mathrm{a}, *}$, Wiem Ben Hassine $^{\mathrm{a}}$, Oualid Limam ${ }^{\mathrm{a}}$, Panagiotis Kotronis ${ }^{\mathrm{b}}$ \\ a University of Tunis El Manar, Laboratory of Civil Engineering (LGC), 'Ecole Nationale d'Ingénieurs de Tunis', B.P. 37, Le Belvédère, 1002 Tunis, Tunisia \\ ${ }^{\mathrm{b}}$ Research Institute in Civil and Mechanical Engineering (GeM), UMR CNRS 6183, Ecole Centrale de Nantes, 1, rue de la Noë, BP 92101, F-44321 Nantes, France
}

\begin{abstract}
Glass-fiber-reinforced concrete (GFRC) has been emerging as a widely used construction material that is suitable for many structural elements and particularly flat slabs. This paper presents mix design proportions of GFRC with $0 \%, 2 \%$ and 3\% weight fractions of fibers and experimental tests including the 3-point bending tests (NT 21.123 (NF P18-407)) which are usually used in practice. These tests provide indirect information on tensile behavior. They are completed by an identification of the tensile behavior made by inverse analysis to obtain it from their bending response. For this purpose, an analytical damage model is developed to obtain bending moment-curvature constitutive behavior. The deduction of load-deflection relationship is established using different beam theories. It is shown that the classical beam theory is sufficient to estimate the behavior of short beams having a span to height ratio equal to 3 according to NT 21.123 recommendations. Finally, the developed model is applied in order to determine ultimate bending moment capacity as function of GFRC flat slab and beam thickness.
\end{abstract}

\section{Introduction}

GFRC is a composite material produced by reinforcement of a cementitious matrix in which short length glass fibers are distributed randomly. The incorporation of glass fibers is getting growing interest as it offers many advantages such as light weight and mechanical performance which has proved high compressive and tensile strengths, toughness and energy absorption $[1,2,4]$.

Nowadays, GFRC has found successful use in architecture and design for non-structural elements (cladding facades, exterior facade skins) as well as in building for structural plate and shell elements especially in the electrical applications [2-4] as telecommunication towers, prefabricated electrical transformer stations, which have been successfully used. Many researchers [5-10] have

\footnotetext{
* Corresponding author.

E-mail address: marwa.loukil@enit.utm.tn (M. Loukil).
}

attempted to develop numerical and analytical models in order to predict the uniaxial tensile behavior response from their experimental tests of advanced cement-based composites like fiberreinforced concrete FRC, high-performance fiber-reinforced concrete HPFRC or ultra-high-performance fiber-reinforced concrete UHPFRC materials $[11,12]$. Because of the complexity of the uniaxial tensile test which needs sophisticated equipment and analyses, bending tests have become the simplest tool to identify the tensile proprieties of FRC.

Previous studies have used the classical diagram Load - CMOD (Crack Mouth Opining Displacement) to obtain stress - CMOD response using notched three-point bending test based on RILEM TC162-TDF (RILEM 2002) [13] and the recommendations of AFGC (French Association of Civil Engineering, 2013) [14]. Others are used the strain -stress constitutive behavior using experimental measurements from unnotched four -point bending tests. A very widely used test for concrete control in Tunisia is the three-point 
bending test corresponding to NT 21.123(1990) (NF P 18-407 (1981)). The indirect experimental results are requiring a second procedure to evaluate the stress-strain behavior of tested materials and to determine their tensile proprieties. Moreover, this procedure needs to use a mechanical model in order to do an inverse analysis determining the tensile behavior law of material from the experimental results obtained in the bending tests. For example, the AFGC (2013) has proposed three inverse analysis methods to obtain the constitutive law of thin UHPFRC elements from unnotched four-point bending test [14]. The first method is called simplified inverse analysis which assumes a bi-linear stress-strain constitutive relationship and consists in an iterative process by varying the constitutive parameters until the analytical curve fits the experimental one. Many researchers focus to develop new simplified methods to improve the AFGC's simplified method by using analytical models based on tri-linear stress-strain constitutive law, quadrilinear, and multi-linear assumptions of the tensile behavior $[5,32,35,36,37]$. The second and the third methods proposed by AFGC use different experimental measurements (strain measurement at the bottom fiber or deflection measurement) as data input in their proposed analytical model. These models not assume a constitutive relationship but they consist to find the associated tensile stress from the set values measured (strain or deflection) at each point step in the test, this method is called point-bypoint inverse analysis [8,14,15,24,37].

Incorporating glass fibers in cementitious matrix seems to be a good substitution of steel reinforced concrete in the building of precast electrical equipment shelters and thin structural elements. For this purpose, this study concerns formulation tests on GFRC for its use in precast slabs or beams for industrial applications. This study is firstly focused on experimental program tests which consist to obtain an optimized material formulation in the aim to design precast elements for electrical shelters. The main objective is to formulate GFRC which is able to reach high compressive and tensile strengths respectively over $80 \mathrm{MPa}$ and $5 \mathrm{MPa}$ after 28 days of age without any steel reinforcement. Mixes proportions have been prepared using three weight fractions of glass fibers $0 \%, 2 \%$ and $3 \%$ using the premixed method. Comparatively to conventional concrete, GFRC is a micro-concrete which is generally characterized by higher contents of cement and fine aggregates. After getting the adequate workability which is measured by a slump test, the glass fibers are added gradually [15]. The mechanical proprieties of GFRC are carried out on cylindrical specimens for compressive tests and on prismatic beams for the three-point bending tests NT 21.123 (NF P18-407)) which are usually used in practice. Secondly, in order to obtain the material behavior law, these tests are completed by an identification of the tensile behavior using an inverse analysis to obtain it from their bending response. The identified simplified constitutive law is an elastic damage behavior with fewer parameters in comparison to sophisticated methods [37] which will lead to an approximation of experimental data but could be easier and more practical to implement in mechanical structural analyses using damage mechanics. The bending moment-curvature behavior law is developed using the classical damage constitutive law proposed by Mazars [17]. For a given beam section, the isotropic elastic damage behavior is integrated on beam section in order to generate the moment-curvature relationship. Therefore, the deduction of load-deflection relationship from the moment-curvature distribution along the beam is established using different beam theories. In addition, a variation of span to height ratio is used to validate the classical beam theory in order to show its sufficiency to estimate the behavior of short beams having a span to height ratio equal to 3 according to NT 21.123 recommendations. After using an optimization tool in order to identify the tensile damage model parameters from the experimental data, the developed model is applied to determine ultimate bending moment capacity used for the design of GFRC flat slab and beams.

\section{Experimental program}

\subsection{Materials and mixture proportions}

The mix design proportions are based on both the multi-Scale Fiber Reinforced Concept developed by Rossi [18] and the recommendations of French Association of Civil Engineering (AFGC) [14]. The design specifications of GFRC takes into consideration these recommendations.

- Sand to Cement ratio is equal to 1 .

- Water to Cement ratio is between 0.27 and 0.34 .

- Admixtures is a plasticizer or super-plasticizer which is generally recommended for fiber reinforced concrete.

- Glass fibers which are distributed randomly and must be added gradually into the mixture $[15,16]$. A weight fraction of glass fibers is recommended from $2 \%$ to $5 \%$ according to the method of manufacturing (Premixed or sprayed-up method).

The aim is to optimize the process in order to find higher compressive and tensile strengths. The cement used is a Portland cement CEM I-42.5 and according to its manufacturer, the cement class strengths were given for 1, 3, 7 and 28 days of age. The compressive strengths were also verified at the same ages according to standard NF P 15-301 (NT 47.30). Table 1 summarizes the specific characteristics and the strengths class of the cement used.

In this experimental study, Natural River sand is obtained from a local quarry. Table 2 summarize their physical characteristics and the size distribution. An alkali resistant glass fibers CEM-FIL 62 [19] (Fig. 1) are used and their physical proprieties are given in Table 3.

The sand to cement ratio and the water to cement ratio are kept constant at 1 and 0.3 respectively for all mixes. In order to obtain a consistency class S3 of concrete destined for precast elements, workability is tested according to NT21.116 (1990) (NF EN 206-1), using Slump test for each mix proportions. In fact, the

Table 1

Physical characteristics of the cement.

\begin{tabular}{|c|c|c|c|}
\hline \multirow[t]{3}{*}{ (NT 47.01) } & \multicolumn{3}{|c|}{ Cement CEM I 42.5} \\
\hline & Specif & & 3.11 \\
\hline & Blaine & $\left.\mathrm{m}^{2} / \mathrm{kg}\right)$ & 340 \\
\hline \multirow[t]{6}{*}{ (NT 47.30) } & \multicolumn{3}{|c|}{ Cement class strengths } \\
\hline & Days & Strength announced by the cement plant (MPa) & Experimental strength (MPa) \\
\hline & 1 & - & 8.1 \\
\hline & 3 & 21 & 21.75 \\
\hline & 7 & 36 & 34.5 \\
\hline & 28 & 50 & 52.8 \\
\hline
\end{tabular}


Table 2

Physical characteristics of the sand used.

\begin{tabular}{lll}
\hline & $\begin{array}{l}\text { River Sand } \\
\text { Sieve analysis }\end{array}$ \\
\cline { 2 - 3 } & Sieve size (mm) & \% Cumulative passing \\
\hline NF EN 933-1 (NT 21-07) & 0.063 & 0.76 \\
& 0.08 & 1.67 \\
& 0.16 & 11.88 \\
& 0.315 & 55.03 \\
& 0.5 & 80.69 \\
& 1.2 & 95.21 \\
& 2.5 & 98.29 \\
NF P 18-554 & 5 & 99.46 \\
NF P 18-597 (NT 21-26) & Absolute density (kg/m $\left.{ }^{3}\right)$ & 2600 \\
NF P 18-555 (NT 21-05) & Absorption capacity (\%) & 85 \\
\hline
\end{tabular}

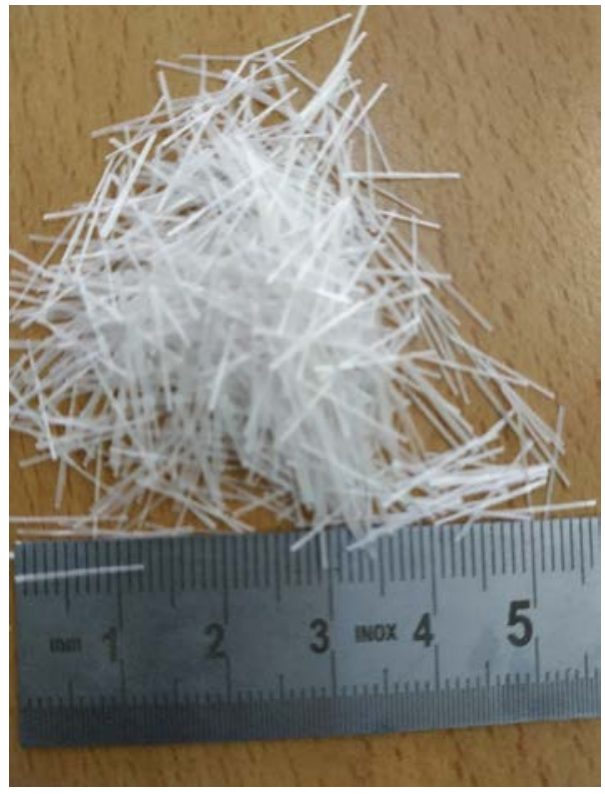

Fig. 1. CEM Fil 62glass fibers.

Table 3

Physical characteristics of glass fiber CEM Fil 62

\begin{tabular}{ll}
\hline Material & Alkali resistant Glass Fiber \\
\hline Diameter & $14 \mu \mathrm{m}$ \\
Length & $12 \mathrm{~mm}$ \\
Specific weight $\left(\mathrm{g} / \mathrm{cm}^{3}\right)$ & 2.68 \\
Color & White \\
Design & Monofilament Fiber \\
Modulus of elasticity (GPa) & 70 \\
Tensile strength $(\mathrm{MPa})$ & 1700 \\
Water uptake & $<0.1 \%$ \\
\hline
\end{tabular}

workability plays an important role of the GFRC mix design and decreases with the addition of glass fibers [20], this difficulty can be overcome by adding superplasticizer ADVA XR3030 provided by a local manufacturer. Three different weight fractions $(0 \%, 2 \%$, $3 \%$ ) of micro-concrete CM, GFRC2 and GFRC3 respectively are adopted to this study. The premix method is used for the same process as that will be performed in the precast GFRC elements in the industry. The mix proportions of the CM, GFRC2 and GFRC3 are shown in Table 4.

\subsection{Mechanical proprieties}

Experimental tests are carried out on GFRC with different weight fractions of fibers in order to determinate the characteristics of this material likes compressive strength, Young's modulus, indirect tensile by three-point bending test (Fig. 2). A total of 21 cylindrical specimens are prepared, with $100 \mathrm{~mm}$ in diameter and $200 \mathrm{~mm}$ in length, and were tested under compressive strength test according to NT 21.113 (NF P18-404) in order to evaluate the compressive strength and the measure of Young 's modulus for 7 and 28 days of age. A series of 18 prismatic specimens with $280 \mathrm{~mm}$ in length and having a cross section of $70 \mathrm{~mm}$ by $70 \mathrm{~mm}$ are carried out under flexural test without unloading for 7 and 28 days of age which is conformed according to the NT 21.123 (NF P 18-407). All specimens were cured in laboratory conditions and at ambient temperature $\left(20 \pm 2{ }^{\circ} \mathrm{C}\right)$.

The Young's modulus was determinate using an electronic extensometer fixed on cylindrical specimens $(100 \mathrm{~mm}$ diameter and $200 \mathrm{~mm}$ height) as illustrated in Fig. 2b. The extensometer used measure the deformation under cyclic loading tests by means of electromechanical compression machine and the Young's modulus was determined from the strain-stress curve after linear fitting of experimental data.

\subsection{Tests results and discussions}

The experimental data of compressive strength tests at 7 and 28 days are shown in Fig. 3. Overall, the GFRC2 represents the highest value of the compressive strength comparing to CM and GFRC3. In fact, an average of $86 \mathrm{MPa}$ is reached for GFRC2 after 28 days of age, while GFRC3 reached only an average of $79 \mathrm{MPa}$. The compressive strength of GFRC has been increased when the fiber incorporation amount is $2 \%$, however further addition of fiber $3 \%$ indicated a slight decrease in compressive strength. This loss of compression strength can be explained by a less compaction of the material associated to spaces occupied by the glass fibers. This was confirmed by Kizilkanat, A and Ghugal, Y [21,22].

Furthermore, the addition of glass fibers increases the Young's modulus. However, from the different values of modulus of elasticity measured at 7 and 28 days of age which is shown in Table 5, a slight decrease in the elastic modulus is expected for GFRC3.

Fig. 4 shows the three-point bending test which is carried out on simply supported beams having a span of $210 \mathrm{~mm}$ under an electro- hydraulic press testing machine through monotonic displacement control at a rate of $0.125 \mathrm{~mm} / \mathrm{min}$ for all specimens. The comparison of the failure mode of two types of beams at the same load stage is different. It can be noticed that micro concrete without fibers CM (Fig. 4-a) has a brittle behavior since it failed the earliest while the reinforced beam with glass fibers

Table 4

Details of mix proportions.

\begin{tabular}{|c|c|c|c|c|c|c|}
\hline \multirow[b]{2}{*}{ Mix design } & \multicolumn{6}{|c|}{ Unit weight $\left(\mathrm{kg} / \mathrm{m}^{3}\right)$} \\
\hline & Cement & Sand & Water & Superplasticizer & Fiber content (by the total weight) & Slump $(\mathrm{cm})$ \\
\hline $\mathrm{CM}$ & 977 & 977 & 293.1 & 4.88 & 0 & 15 \\
\hline GFRC2 & 948 & 948 & 284.4 & 9.48 & 44 & 12.5 \\
\hline GFRC3 & 948 & 948 & 284.4 & 12.32 & 66 & 11 \\
\hline
\end{tabular}




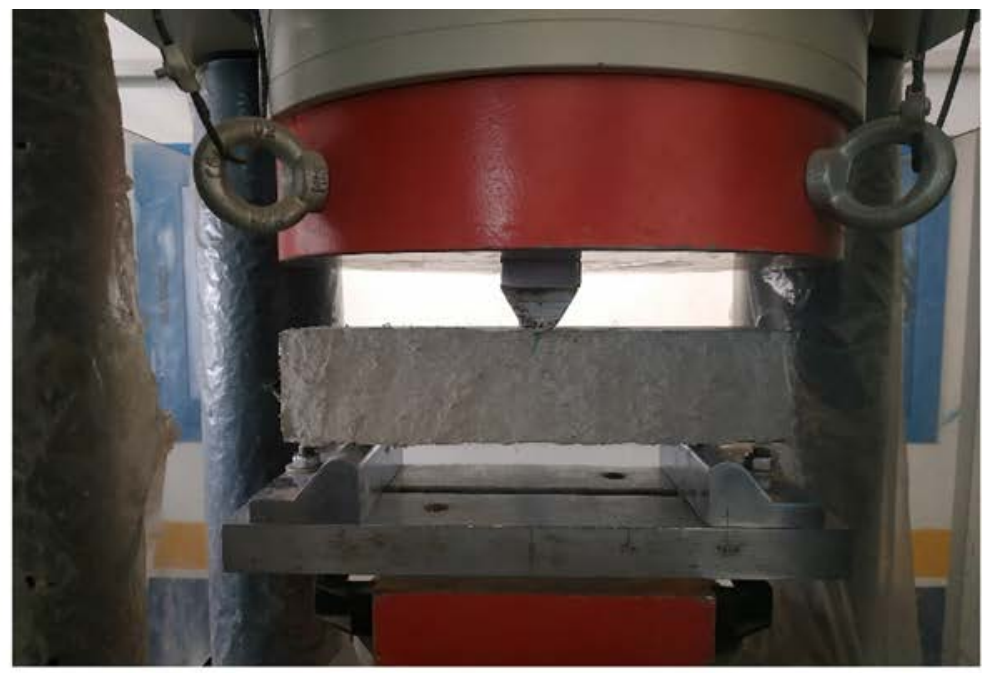

$\mathbf{a}$

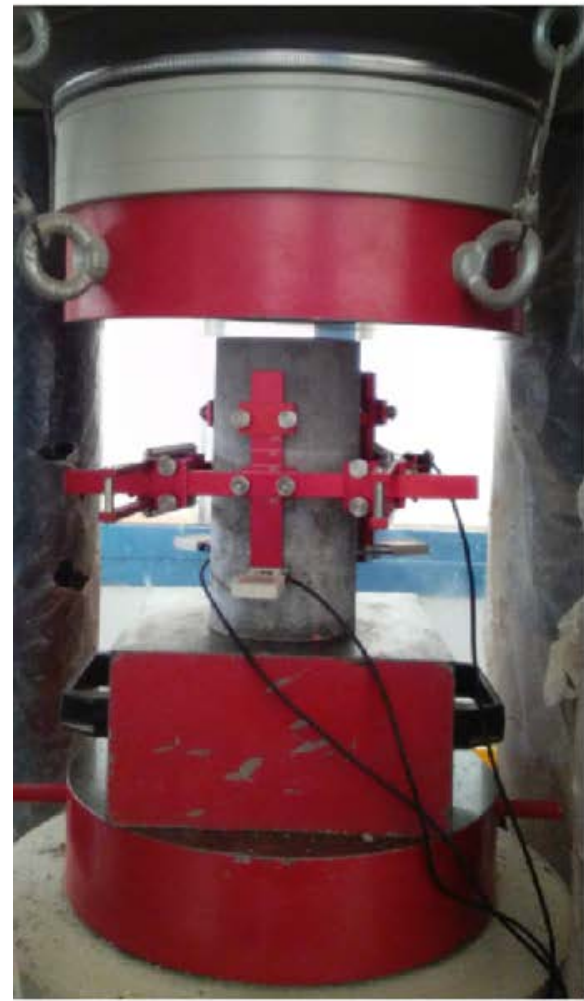

b

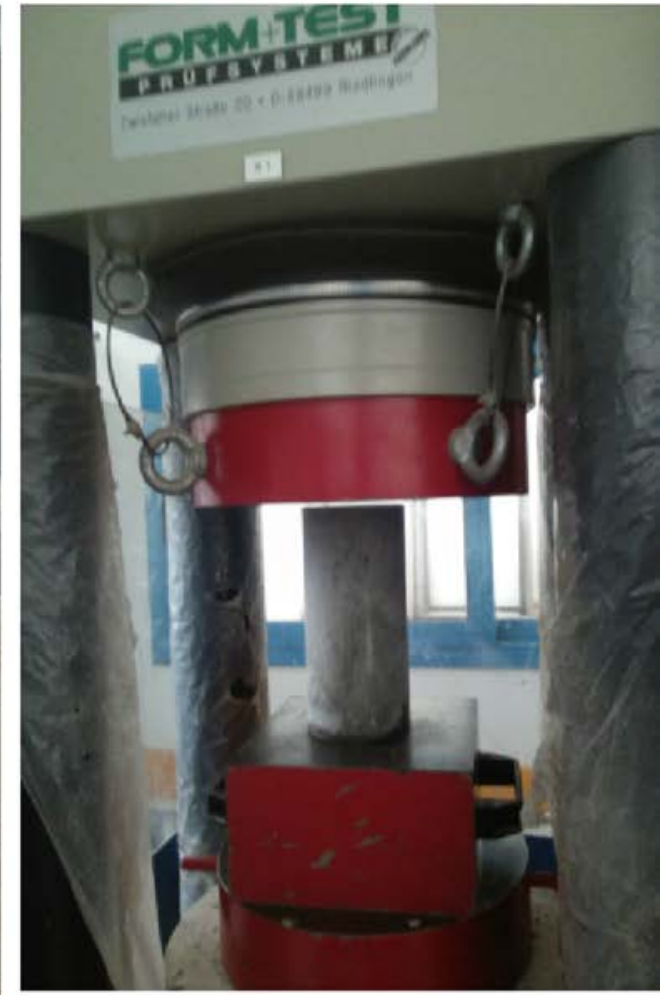

c

Fig. 2. Performed mechanical tests. a - Three-point bending test. b - Electronic extensometer. c - Compressive test.

is more ductile where fibers prevent crack propagation. It can be seen from the Fig. 4-b that flexural cracks appear at the midspan at the bottom and propagated in a larger zone to the top of the beam.

As illustrated in Fig. 5, a visually observation shows a uniform distribution in space of these short fibers $(1 / \varnothing=857)$ throughout the concrete matrix which indicates a macro-homogeneity of the material. The main advantages of glass fibers are their low density and their ability to be dispersed uniformly and randomly oriented within the matrix. In fact, it was shown that the distribution of the fibers and the fibers segregation influence significantly on the mechanical properties of the material especially in the tensile post-cracking parameters which are necessary for the design of structures [16,34].

The evolution of the three-point flexural strength at 28 days of age versus imposed deflection at mid-span is represented in Fig. 6. These Fig. 6-a, 6-b and 6-c illustrate the load -vertical displacement behavior for CM, GFRC2 and GFRC3 respectively. It is shown that GFRC2 and GFRC3 have more ductile behavior comparing to CM which shows a brittle failure. The maximum load and the maximum deflection obtained for each mix are summarized in Table 6. It is clear that the addition of glass fibers has an important role to increase the bending capacity and to inhibit the developing of cracks and microcracks. On the contrary to compressive strength 


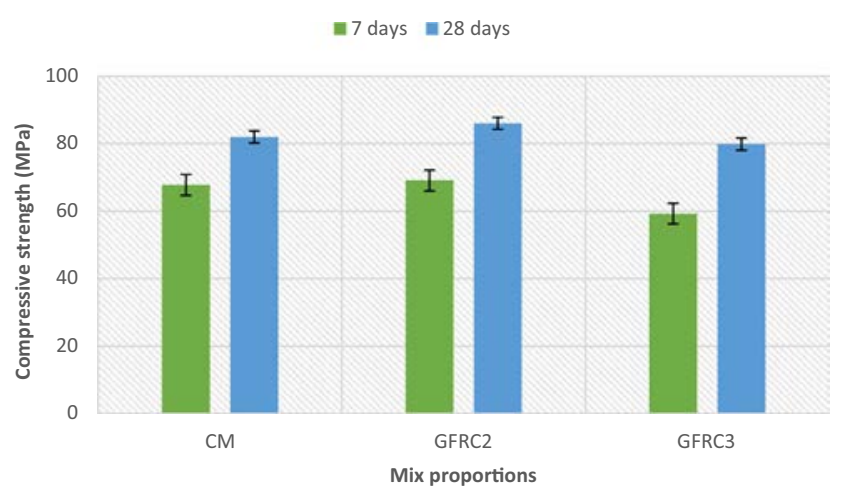

Fig. 3. Analysis of compressive strength test results at 7 and 28 days of age.

Table 5

Modulus of elasticity results.

\begin{tabular}{llll}
\hline Young's modulus (MPa) & \multicolumn{2}{l}{ Mix design } & \\
\cline { 2 - 4 } & CM & GFRC2 & GFRC3 \\
\hline 7 Days & 29700 & 31333 & 30966 \\
28 Days & 33498 & 35043 & 34851 \\
\hline
\end{tabular}

tests, GFRC3 shows higher strength and dissipative energy capacity than GFRC2 in tension.

\section{Analytical modelling of three-point bending test}

Consider a simple supported beam with rectangular cross section $(\mathrm{b} \times \mathrm{h})$ subjected to an imposed increasing displacement $\mathrm{v}$ $(\mathrm{L} / 2)$ without unloading where $\mathrm{F}$ denotes the associated force as represented in Fig. 7.

\subsection{Bending moment-curvature relationship}

In order to model the flexural behavior of beams, a simplified scalar damage constitutive law proposed by Mazars et al $[17,23]$ is adopted in uniaxial tension to deduce the bending moment-curvature relationship. The strain -stress relationship of the Mazars' model is given by Eq. (1)

$\sigma_{\mathrm{t}}=\mathrm{E}\left(1-\mathrm{D}_{\mathrm{t}}\right) \varepsilon_{\mathrm{t}}$

where $\mathrm{E}$ is the Young's modulus of the undammged material, $\varepsilon_{\mathrm{t}}$ is the tensile strain and $D_{t}$ represents the scalar damage variable describing the damage states. It ranges from 0 for a virgin state to 1 at failure. The evolution of damage is defined in Eq. (2).

$\mathrm{D}_{\mathrm{t}}= \begin{cases}0 & \text { if } \varepsilon \leqslant \varepsilon_{\mathrm{d} 0} \\ 1-\frac{\varepsilon_{\mathrm{d} 0}\left(1-\mathrm{A}_{\mathrm{t}}\right)}{\varepsilon}-\frac{\mathrm{A}_{\mathrm{t}}}{\mathrm{e}^{\mathrm{B}_{\mathrm{t}}\left(\varepsilon-\varepsilon_{\mathrm{d} 0}\right)}} & \text { if } \varepsilon>\varepsilon_{\mathrm{d} 0}\end{cases}$

With $A_{t}$ and $B_{t}$ are the parameters of the damage model which should be identified from tensile experimental tests and allowing the shape of the curve in the post peak. $\varepsilon_{\mathrm{do}}$ is the elastic strain threshold corresponding to the beginning of the damage. $\varepsilon$ is the maximum value of $\varepsilon_{\mathrm{t}}$ ever reached in the history of loading or unloading and always leading to an increase of damage $\left(\dot{D}_{t}>0\right)$.

We consider first the classical beam theory kinematic assumptions with an axial strain in the beam varying linearly through the thickness. In the elastic area, like presented in Fig. 8, a linear distribution of stress in the compressive zone and at the beginning of the tensile zone is defined until the tensile strength will be reached. In the case of classical beam theory, the axial strain at a distance $y$ from the neutral axis of the beam is given by Eq. (3).

$\varepsilon_{\mathrm{t}}=\chi y$

where $\chi=\frac{\mathrm{d} \phi}{\mathrm{dx}}$ is the curvature of the deformed beam which is defined as the derivative of the section rotation noted $\phi$.

The normal force $\mathrm{N}$ and the bending moment $\mathrm{M}$ are given by Eqs. (4a) and (4b):

$\mathrm{N}=\int_{-\frac{b}{2}}^{\frac{b}{2}} \int_{-(\mathrm{h}-\overline{\mathrm{y}})}^{y^{-}} \sigma_{\mathrm{t}} \mathrm{dzdy}=\mathrm{b} \int_{-\mathrm{h}+\overline{\mathrm{y}}}^{y^{-}} \mathrm{E}\left(1-\mathrm{D}_{\mathrm{t}}\right) \varepsilon_{\mathrm{t}} \mathrm{dy}$

$\mathrm{M}=\int_{-\frac{\mathrm{b}}{2}}^{\frac{\mathrm{b}}{2}} \int_{-(\mathrm{h}-\overline{\mathrm{y}})}^{y^{-}} \sigma_{\mathrm{t}} \mathrm{dzdy}=\mathrm{b} \int_{-\mathrm{h}+\overline{\mathrm{y}}}^{y^{-}} \mathrm{E}\left(1-\mathrm{D}_{\mathrm{t}}\right) \varepsilon_{\mathrm{t}} \mathrm{ydy}$

Substituting Eq. (2) and Eq. (3) into Eqs. (4a) and (4b) and knowing that the normal force $\mathrm{N}$ must be equal to zero. Eq. (4) yield to the following system composed by Eq. (5) and Eq. (6).

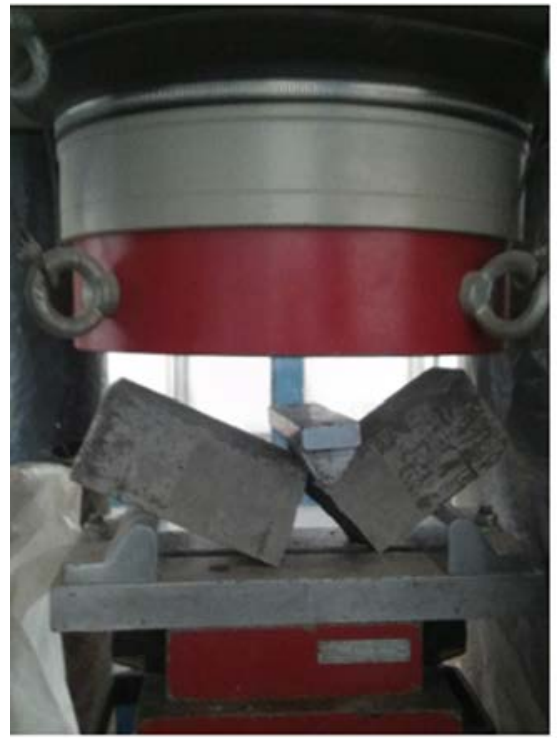

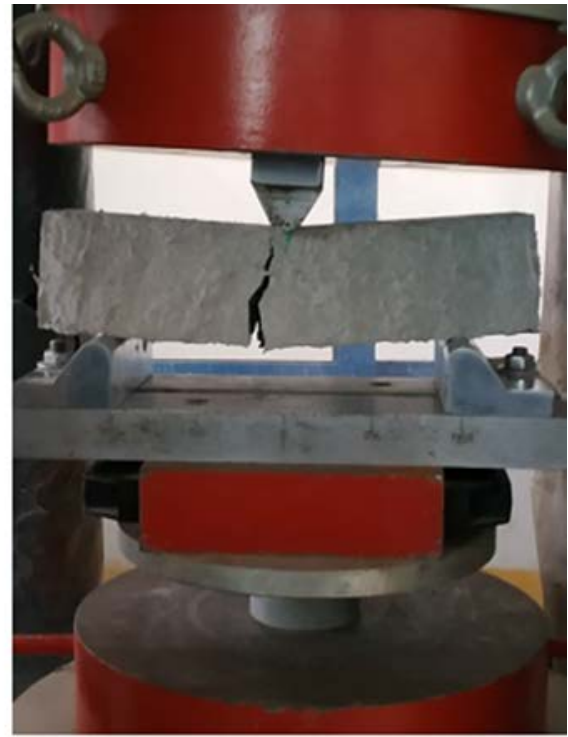

$\mathbf{b}$

Fig. 4. Three-point bending test, a - specimen without glass fibers, b - specimen with glass fibers. 


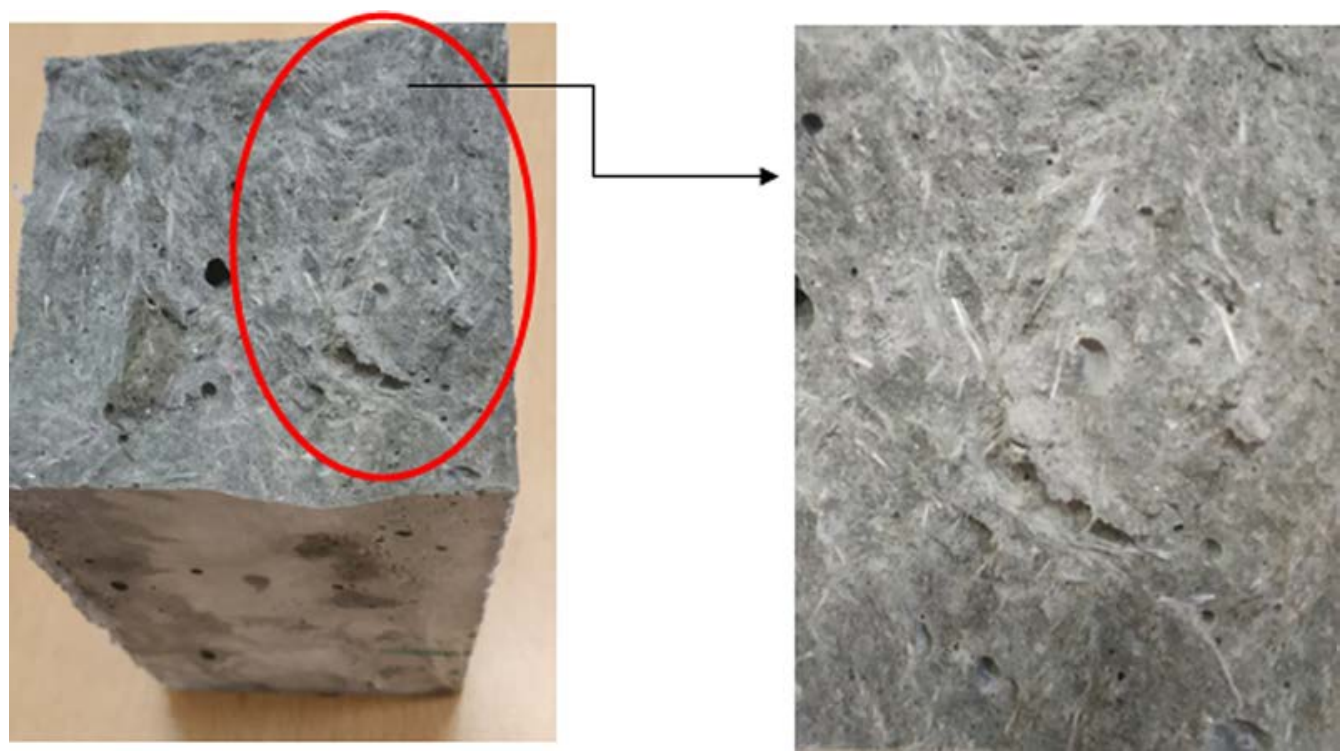

Fig. 5. Homogeneous and uniform distribution of glass fibers in the matrix.

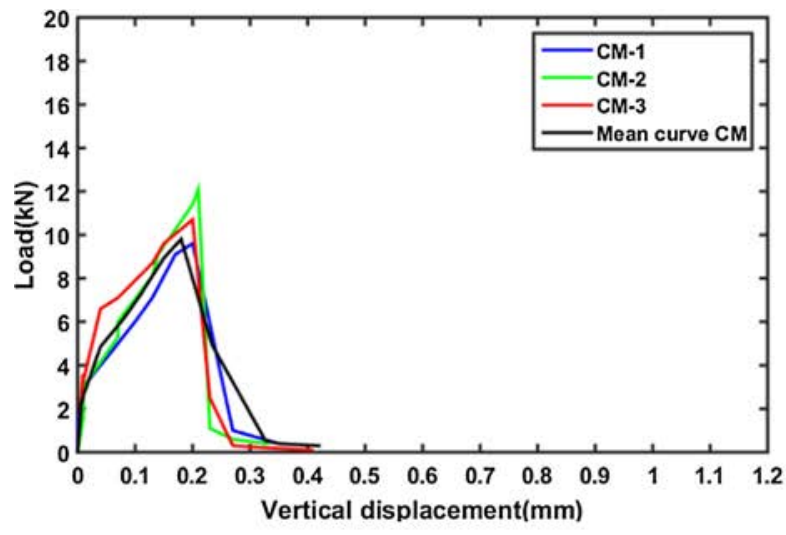

a

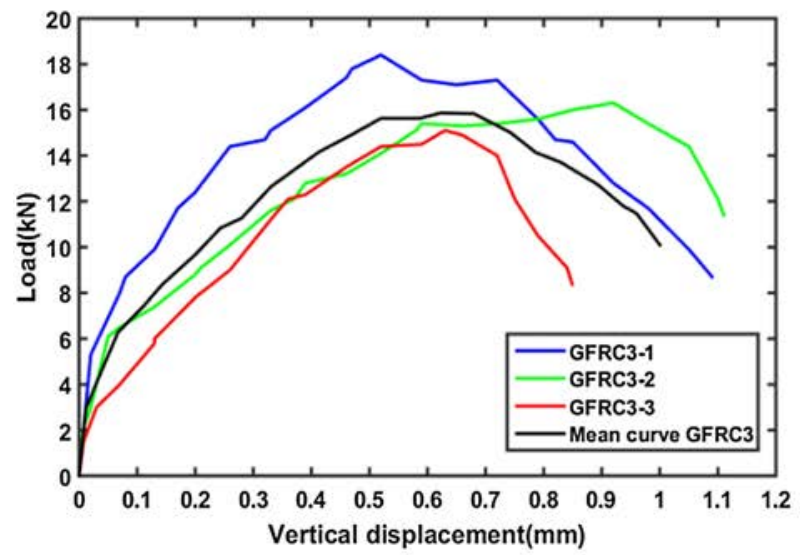

c

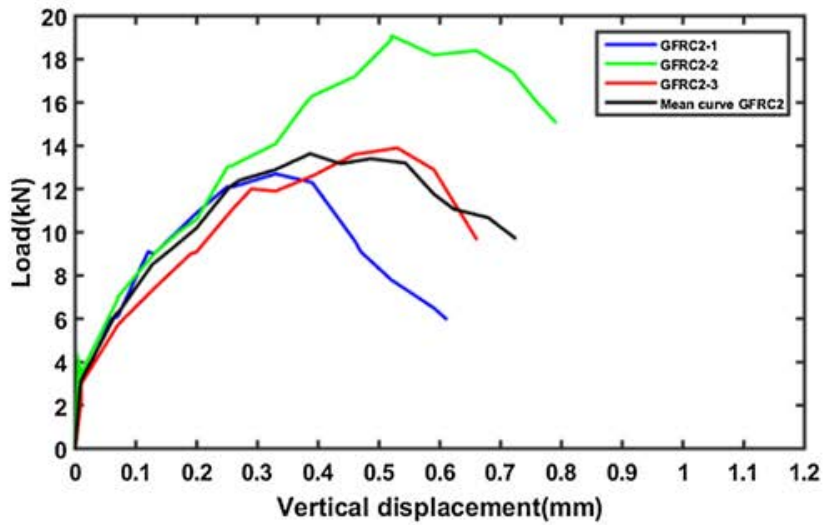

b

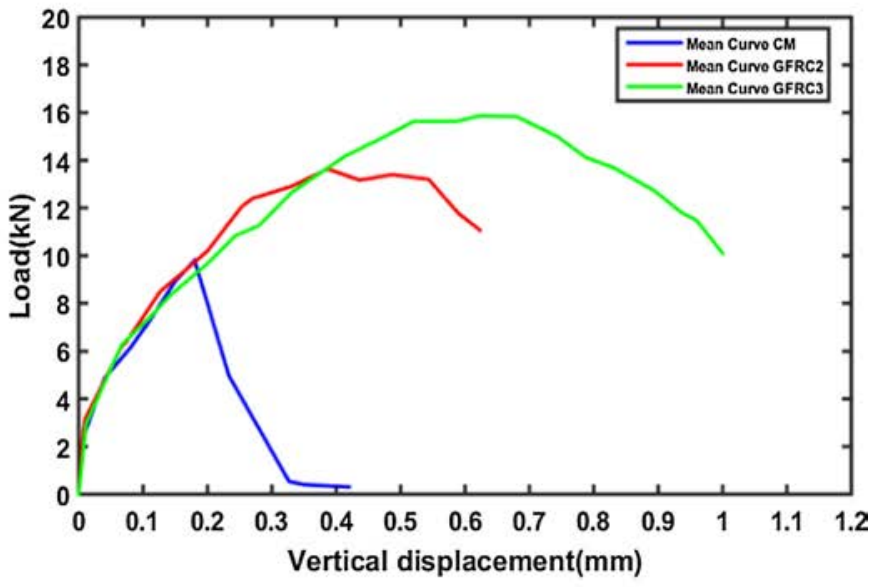

d

Fig. 6. Load-displacement for three-point bending test, a - CM, b - GFRC2, c - GRRC3, d - Mean curves at 28 days of age. 
Table 6

Characteristic values of load-deflection curves.

\begin{tabular}{|c|c|c|c|c|}
\hline & & $\mathrm{CM}$ & GFRC2 & GFRC3 \\
\hline \multirow[t]{4}{*}{ Maximum Load F (kN) } & $\mathrm{F} 1$ & 9.6 & 12.3 & 17.1 \\
\hline & F2 & 9.1 & 12.6 & 15.4 \\
\hline & F3 & 10.7 & 16 & 15.1 \\
\hline & $F_{\text {mean }}$ & 9.8 & 13.63 & 15.86 \\
\hline Standard deviation & & 0.66 & 1.6 & 0.88 \\
\hline \multirow[t]{4}{*}{ Deflection at max load (mm) } & d1 & 0.2 & 0.39 & 0.65 \\
\hline & $\mathrm{d} 2$ & 0.14 & 0.39 & 0.59 \\
\hline & d3 & 0.2 & 0.38 & 0.63 \\
\hline & $\mathrm{d}_{\text {mean }}$ & 0.18 & 0.38 & 0.623 \\
\hline Standard deviation & & 0.028 & 0.008 & 0.024 \\
\hline
\end{tabular}

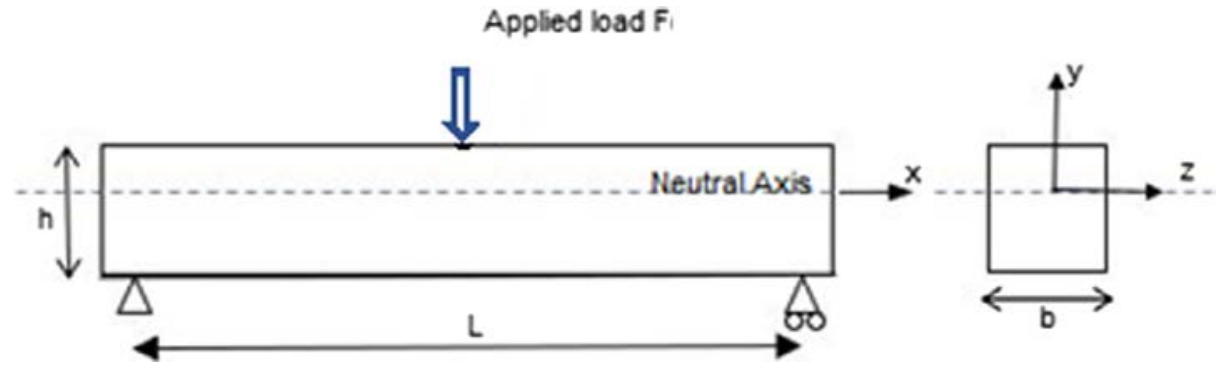

Fig. 7. Beam under bending in $x-y$ plane.

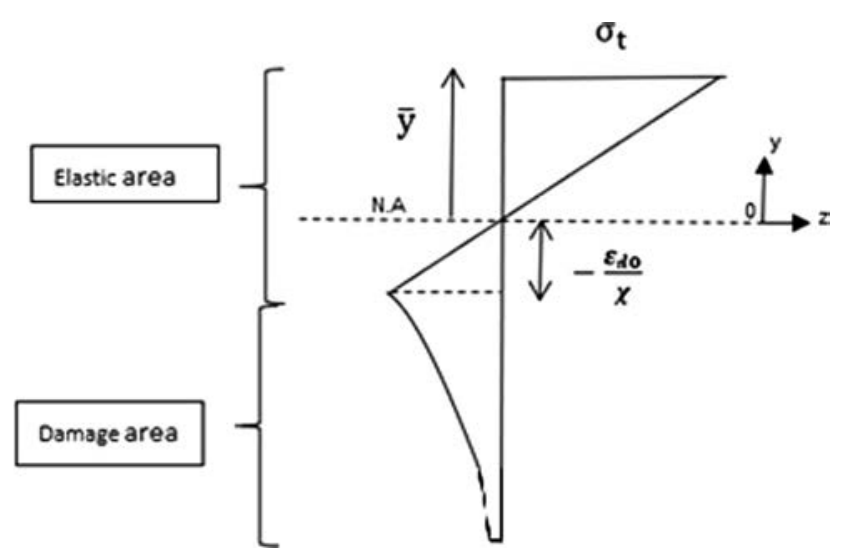

Fig. 8. Stress distribution in the cross section.

$$
\begin{aligned}
\mathrm{N}= & \frac{1}{2} \bar{y}^{2}-\frac{\varepsilon_{d 0}^{2}}{2 \chi^{2}}-\frac{\varepsilon_{d 0}\left(1-A_{t}\right)}{\chi}\left(-\frac{\varepsilon_{d 0}}{\chi}+(h-\bar{y})\right) \\
& +\frac{A_{t} e^{B_{t} \varepsilon_{d 0}}}{B_{t} \chi}\left(\left(-\frac{\varepsilon_{d 0}}{\chi}-\frac{1}{B_{t} \chi}\right) e^{-\varepsilon_{d 0} B_{t}}+\left((h-\bar{y})+\frac{1}{B_{t} \chi}\right) e^{-B_{t} \chi\left(h-y^{-}\right)}\right)=0
\end{aligned}
$$

$$
\begin{aligned}
\mathrm{M}= & \mathrm{bE} \chi\left[\frac{1}{3} \bar{y}^{3}+\frac{\varepsilon_{d 0}{ }^{3}}{9 \chi^{3}}-\frac{1}{2} \frac{\varepsilon_{d 0}}{\chi}\left(1-A_{t}\right)\left(\frac{\varepsilon_{d 0}{ }^{2}}{\chi^{2}}-(\mathrm{h}-\bar{y})^{2}\right)\right. \\
& +\frac{A_{t} e^{B_{t} \varepsilon_{d 0}}}{B_{t}^{3} \chi^{3}}\left(e^{-B_{t} \varepsilon_{d 0}}\left(\mathrm{~B}_{t}^{2} \varepsilon_{d 0}^{2}+2 \mathrm{~B}_{t} \varepsilon_{d 0}+2\right)-e^{\mathrm{B}_{t} \chi\left(y^{-}-h\right)}\left(\mathrm{B}_{t}^{2} \chi^{2}(\bar{y}-h)^{2}\right.\right. \\
& \left.\left.\left.-2 \mathrm{~B}_{t} \chi(\bar{y}-h)+2\right)\right)\right]
\end{aligned}
$$

In the damage phase, this system must be solved to find the curvature $\chi$ and the depth of the neutral axisy(Fig. 8). It is solved numerically using the proposed incremental and iterative procedure. Fig. 9 well describes the process used.

The details of this procedure are represented in Appendix A.

\subsection{Bending load-deflection relationship}

Based on beam theories and continuum local damage mechanics, this part is describing the development of nonlinear analysis in order to determine the load-midspan deflection relationship from the moment-curvature relationship.

\subsubsection{Elastic phase}

A study of literature [25-29] indicates that many researchers who are dealing with flexural problems of thick homogeneous isotropic beams used generally refined shear deformation theories. For this case, three theories of beams are considered: the classical beam theory CBT (Bernoulli beam theory), the shear deformation theory $[26,27]$ (Timoshenko beam theory) and a higher order shear deformation theory (Levinson beam theory) $[28,29]$. Classical beam theory is the most widely model used and is founded on assumptions which are the plane sections still remain plane and perpendicular to the longitudinal axis of the beam after deformations. In the following study, two-dimensional displacements field $\mathrm{u}(\mathrm{x}$, $\mathrm{y}), \mathrm{v}(\mathrm{x}, \mathrm{y})$ are defined which are the axial and the transverse displacement components respectively of an arbitrary beam material point.

The equilibrium and compatibility Equations of Euler-Bernoulli beam theory are written as follows:

$\chi(\mathrm{x})=\mathrm{v}^{\prime \prime}(\mathrm{x}) ; \quad \chi(\mathrm{x})=\phi^{\prime}(\mathrm{x}) ; \quad \phi(\mathrm{x})=\mathrm{v}^{\prime}(\mathrm{x})$

Furthermore, Timoshenko beam theory is the first order shear deformation theory which includes refined effects such shear deformation effects which are neglected in the classical beam theory. In this theory, transverse shear strain distribution is assumed to be constant through the beam thickness and thus requires problem dependent shear correction factor. However, the limitations of the classical beam theory and the first order shear deformation theory led to the development of higher order shear deformation theories. Levinson and Reddy [27,28] are the first to develop a new beam theory which includes warping of the cross -section. Levinson beam theory predicts the same result for the neutral surface deflection as Timoshenko theory which underestimates deflection associated to shear by $20 \%$ [28]. 


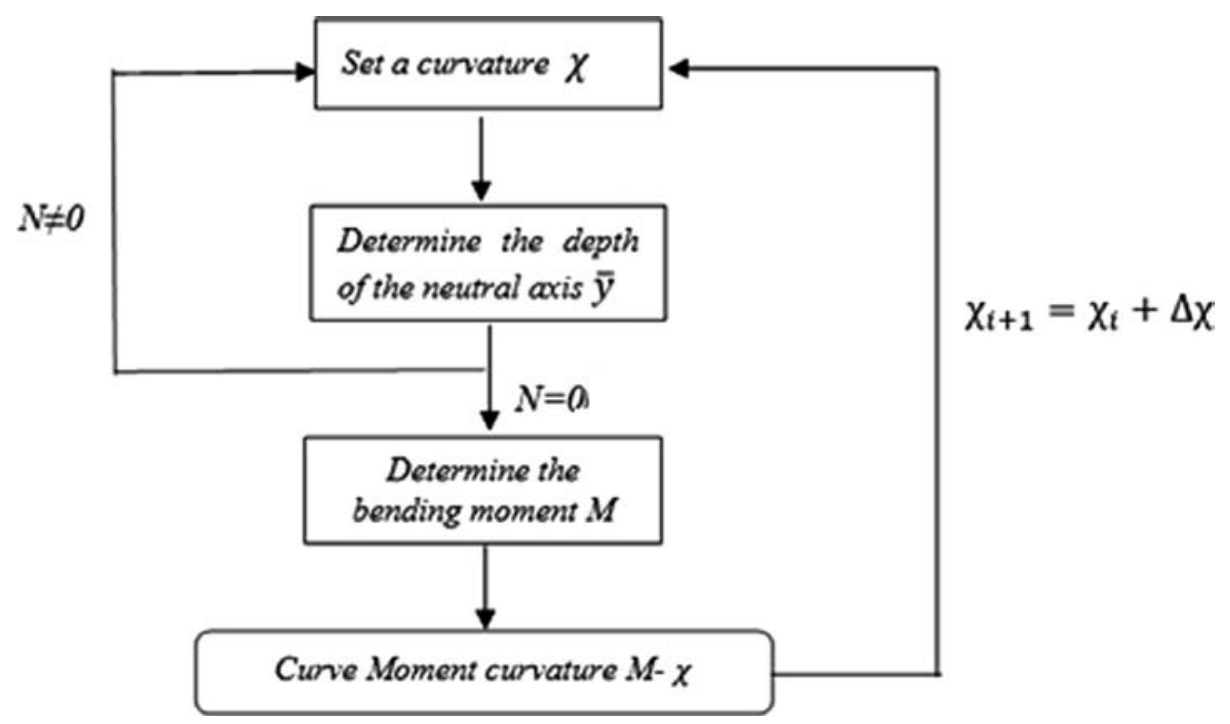

Fig. 9. Procedure for moment curvature relationship.

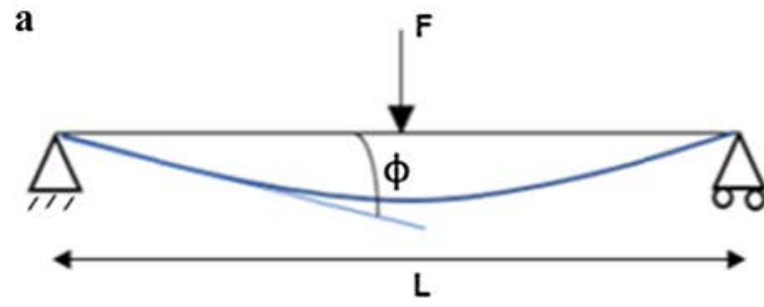

c

b

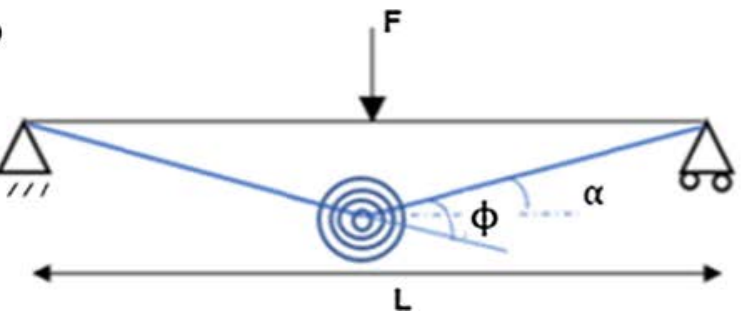

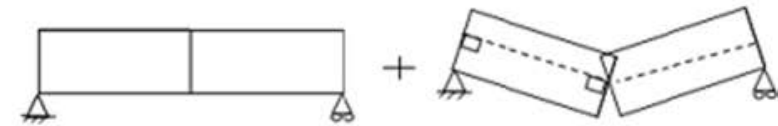

Timoshenko beam theory

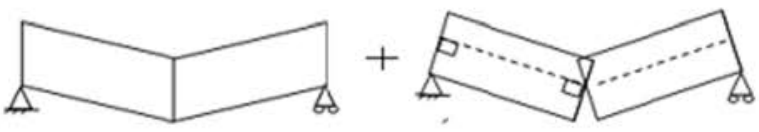

Levinson berm theory

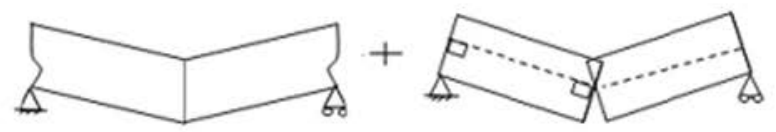

Fig. 10. Simplified equivalent damage model. a - Deflection in elasticity, b - deflection in damage, c - deformed field of beam in damage phase.

For the Levinson beam theory, the displacement field is mentioned in Eq. (8).

$\mathrm{u}(\mathrm{x}, \mathrm{y})=\mathrm{y}\left(\phi(\mathrm{x})-\mathrm{f}(\mathrm{y})\left(\phi(\mathrm{x})+\frac{\mathrm{dv}}{\mathrm{dx}}\right)\right)$

$\mathrm{v}(\mathrm{x}, \mathrm{y})=\mathrm{v}(\mathrm{x})$

where $f(y)$ is the function which describes the displacement distribution through the thickness of the beam. It represents the warping phenomenon.

According to the expression of the warping function $f(y)$, it seems to be easy to present the displacement field of some models of beam theories.
- For the Euler-Bernoulli beam theory, $\mathrm{f}(\mathrm{y})=1$

- For the Timoshenko beam theory, $\mathrm{f}(\mathrm{y})=0$

- For the Levinson beam theory, $f(y)=\frac{4 \mathrm{y}^{2}}{3 \mathrm{~h}^{2}}$

\subsubsection{Post peak phase}

In the post peak phase, a simplified system model is considered in order to find an analogy between the damage bending behavior of the beam and the equivalent system. Loaded by a vertical force $F$ in the middle, the beam is discretized by two segments of length $\mathrm{L} / 2$ which are related by a torsional spring where the damage is supposed concentrated in a single section analogously to plastic hinges. This is in agreement with the experimentally observation failure mechanism where cracks are clustered at the mid-span (Fig. 4-b). The symmetry of the problem induces that the section 
Table 7

Relationship between deflection and curvature.

\begin{tabular}{|c|c|c|c|}
\hline \multirow[t]{2}{*}{ Maximum transverse displacement at mid-span } & \multicolumn{3}{|l|}{ Beam theories } \\
\hline & Bernoulli & Timoshenko & Levinson \\
\hline Elastic phase & $\mathrm{v}=\frac{\mathrm{L}^{2}}{12} \chi_{\mathrm{L} / 2}$ & $\mathrm{v}(\mathrm{L} / 2)=\frac{\mathrm{L}^{2}}{12} \chi_{\mathrm{L} / 2}+\frac{\mathrm{M}(\mathrm{L} / 2)}{\mathrm{kGA}}$ & $\mathrm{v}(\mathrm{L} / 2)=\frac{\mathrm{L}^{2}}{12} \chi_{\mathrm{L} / 2}+1.2 \frac{\mathrm{M}(\mathrm{L} / 2)}{\mathrm{kGA}}$ \\
\hline Post peak phase & $\mathrm{v}(\mathrm{L} / 2)=\frac{\mathrm{L}^{2}}{8} \chi_{\mathrm{L} / 2}$ & $\mathrm{v}(\mathrm{L} / 2)=\frac{\mathrm{L}^{2}}{8} \chi_{\mathrm{L} / 2}+\frac{\mathrm{M}(\mathrm{L} / 2)}{\mathrm{kGA}}$ & $\mathrm{v}(\mathrm{L} / 2)=\frac{\mathrm{L}^{2}}{8} \chi_{\mathrm{L} / 2}+1.2 \frac{\mathrm{M}(\mathrm{L} / 2)}{\mathrm{kGA}}$ \\
\hline
\end{tabular}

Where $\mathrm{G}=\frac{\mathrm{E}}{2(1+v)}$ is the shear modulus, $v$ is the Poisson's ratio $(v=0.2), \mathbf{A}$ is the section's area and $\mathbf{k}$ is the correction factor for rectangular cross section equal to $5 / 6$.
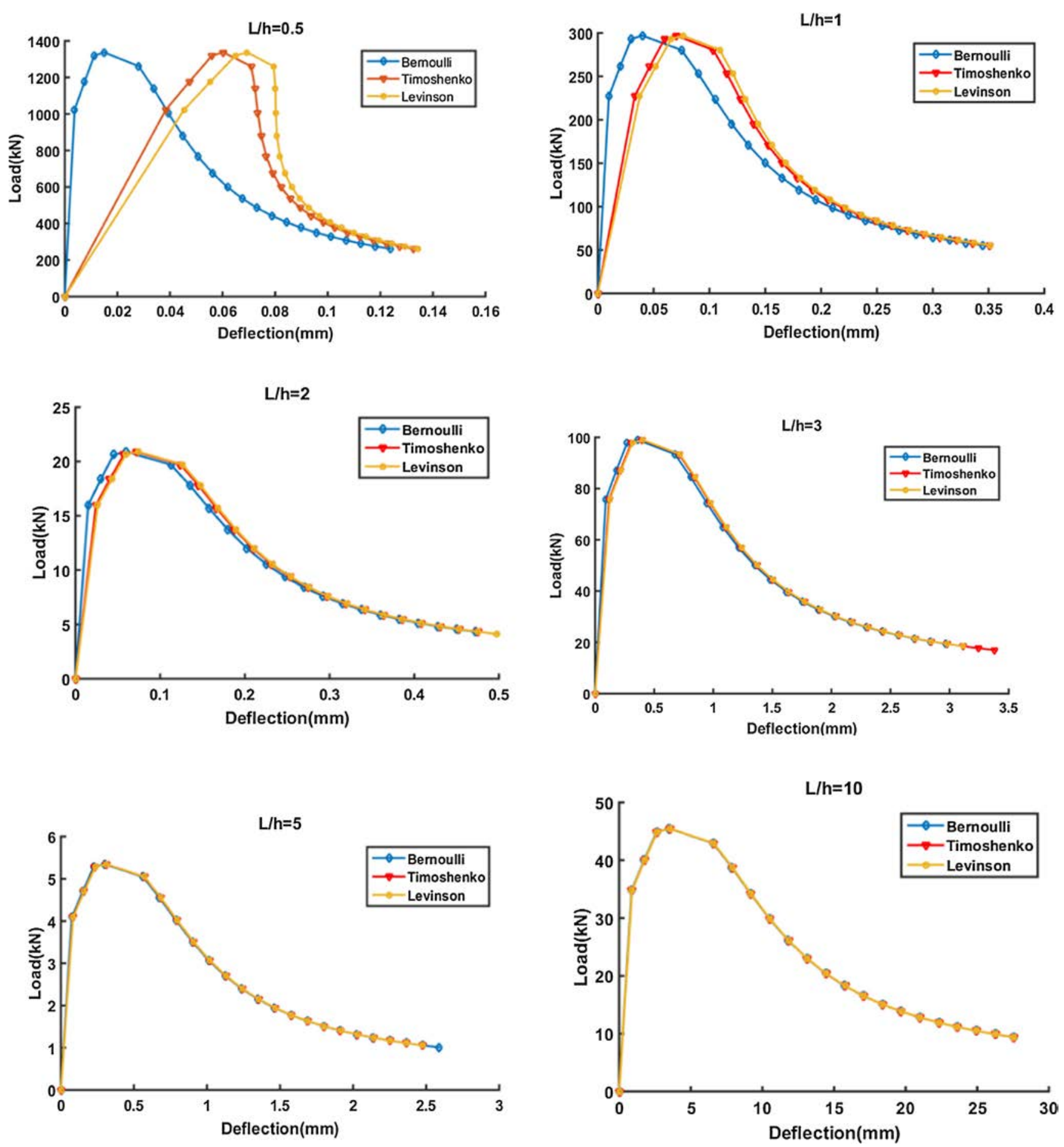

Fig. 11. Load-Deflection curves using different beam theories and different $(\mathrm{L} / \mathrm{h})$ ratios. 


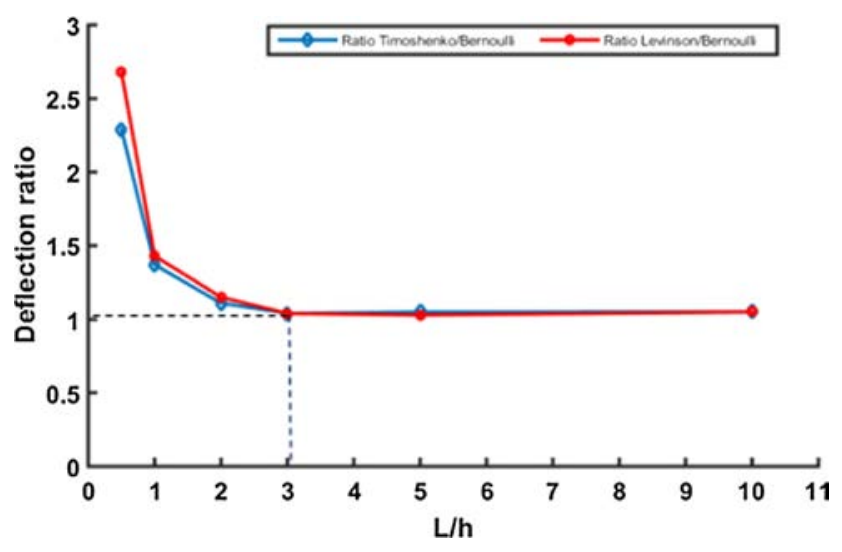

Fig. 12. Effect of shear and warping on total deflection for different $\mathrm{L} / \mathrm{h}$ ratios

in the mid-span remains plane after deformation with a null shear force. So, at the post peak damage phase where bending deformation is supposed to be concentrated at the mid -span where the shear strain vanishes and the three models have the same moment-curvature behavior defined previously in Section 3.1 for the classical beam theory (Fig. 10-c). Elastic shear deformation corresponding to the three beam theories are considered in segments ] $0, \frac{L}{2}[$ and $] \frac{L}{2}, L[$.

In the rigid motion displacement (Fig. 10-b),2 $\alpha$ is the rotation of the spring and due to rotation's discontinuity, the transverse dis- placement and the concentrated curvature at the mid-span can be expressed by Eqs. (9a) and (9b) [30,31].

For the assumption of small displacement:

$\tan \alpha \approx \alpha \mathrm{v}(\mathrm{L} / 2)=\frac{\alpha \mathrm{L}}{2}$

And from the reference [31],

$\chi_{\mathrm{L} / 2}=\frac{4 \alpha}{\mathrm{L}}$

The relation between the maximum transverse displacement and the curvature at $\mathrm{x}=\mathrm{L} / 2$ using the three models of beam theories are defined in Table 7.

\subsection{Validation and discussion}

The proposed damage model is applied using the three different beam theories with the same mechanical parameters of a conventionnel concrete $\left(E=28500 \mathrm{MPa} ; \mathrm{v}=0.2 ; \varepsilon_{\mathrm{d} 0}=1.510^{-4} ; \mathrm{A}_{\mathrm{t}}=0.75\right.$; $\left.B_{t}=7500\right)$. Six different aspects span to height ratio $L / h(0.5 ; 1$; $2 ; 3 ; 5 ; 10)$ are used to calculate the total transverse displacement using the relationship between the deflection and the curvature at $\mathrm{x}=\mathrm{L} / 2$ which are summarized in Table 7 .

The load-displacement curves using different theories and different geometries of beams are shown in Fig. 11. The variation of span to height ratio is investigated in order to highlight the influence of shear and warping. It is clear that the effect of shear strain

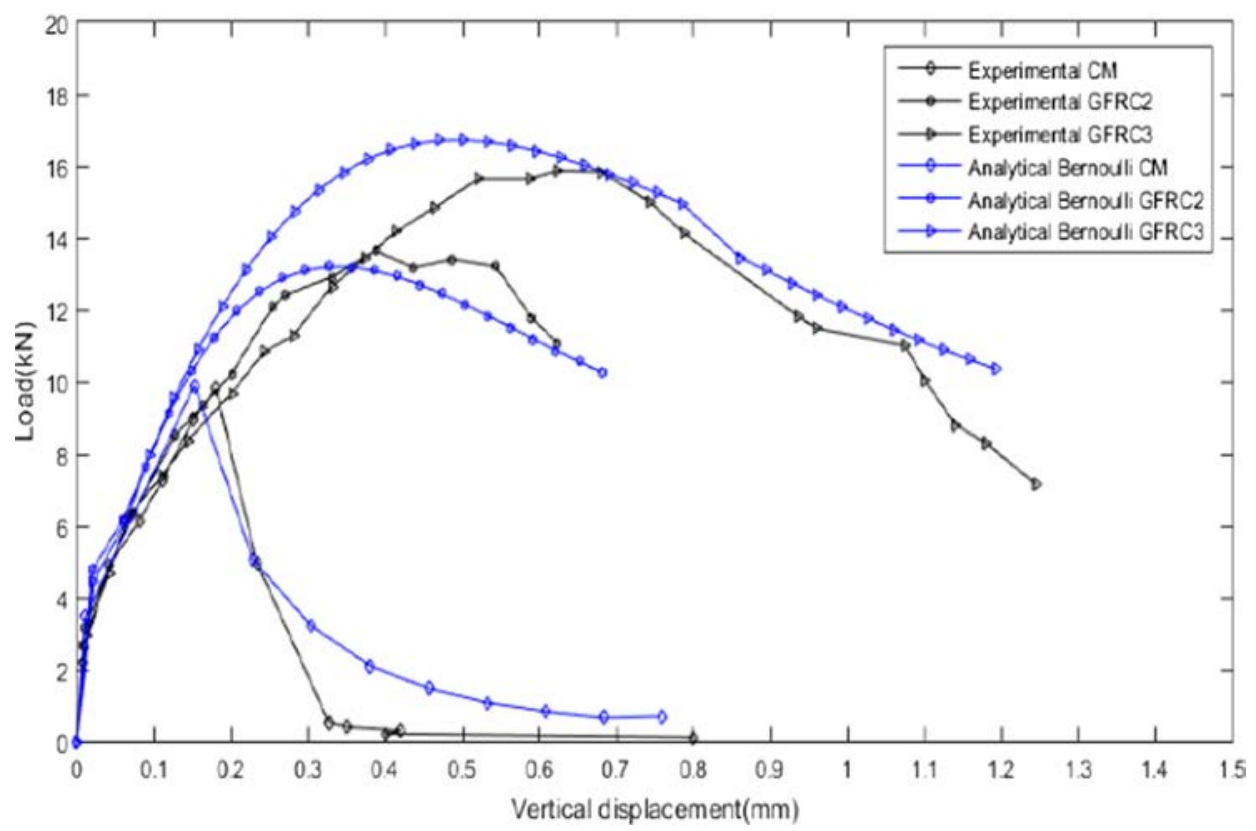

Fig. 13. Load -vertical displacement analytical vs experimental curves Superposition using analytical Bernoulli's beam theory.

Table 8

Tensile parameters values after identification.

\begin{tabular}{|c|c|c|c|c|}
\hline & & \multicolumn{3}{|l|}{ Mix design } \\
\hline & & $\mathrm{CM}$ & GFRC2 & GFRC3 \\
\hline Parameters & $\begin{array}{l}\varepsilon_{\mathrm{d} 0} \\
\mathrm{~A}_{\mathrm{t}} \\
\mathrm{B}_{\mathrm{t}}\end{array}$ & $\begin{array}{l}1.82 \cdot 10^{-4} \\
1 \\
14256\end{array}$ & $\begin{array}{l}2.10^{-4} \\
0.4 \\
750\end{array}$ & $\begin{array}{l}2.110^{-4} \\
0.35 \\
450\end{array}$ \\
\hline
\end{tabular}




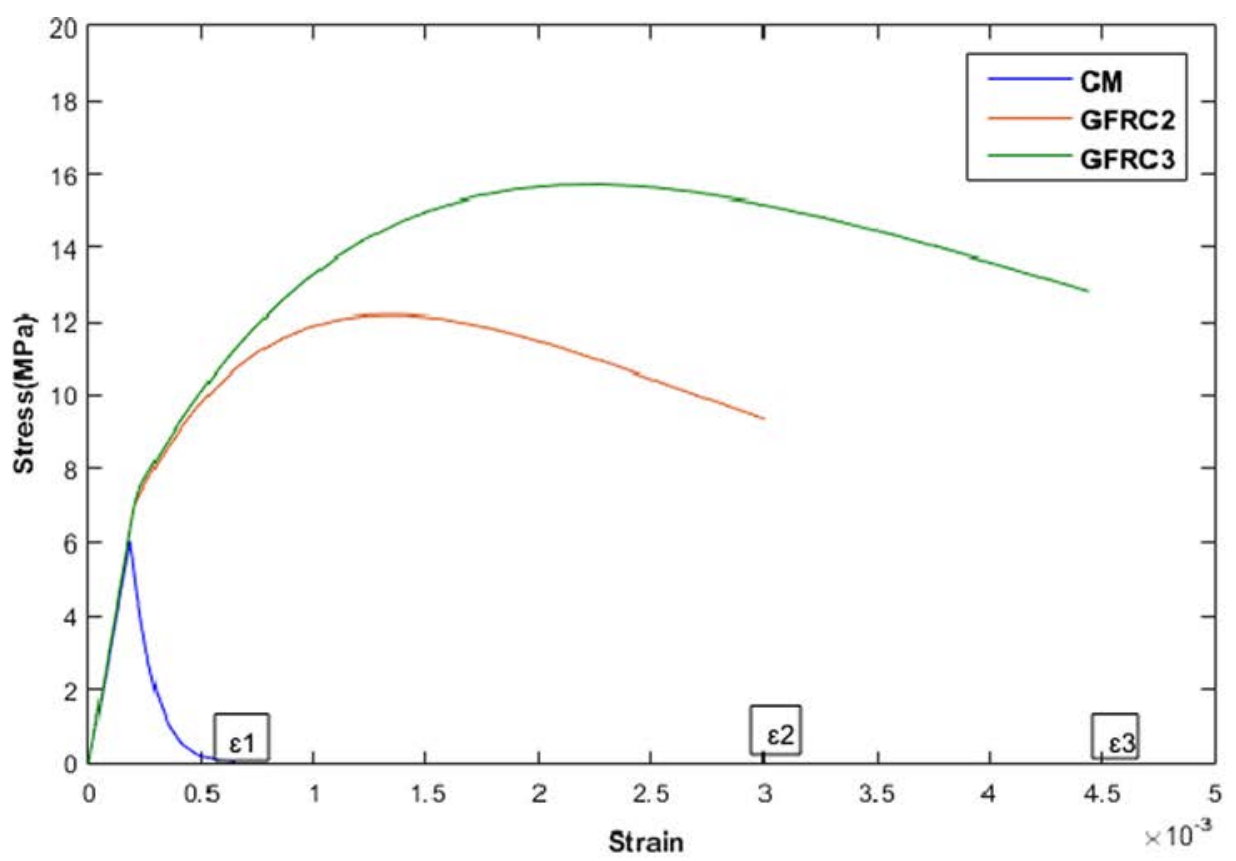

a

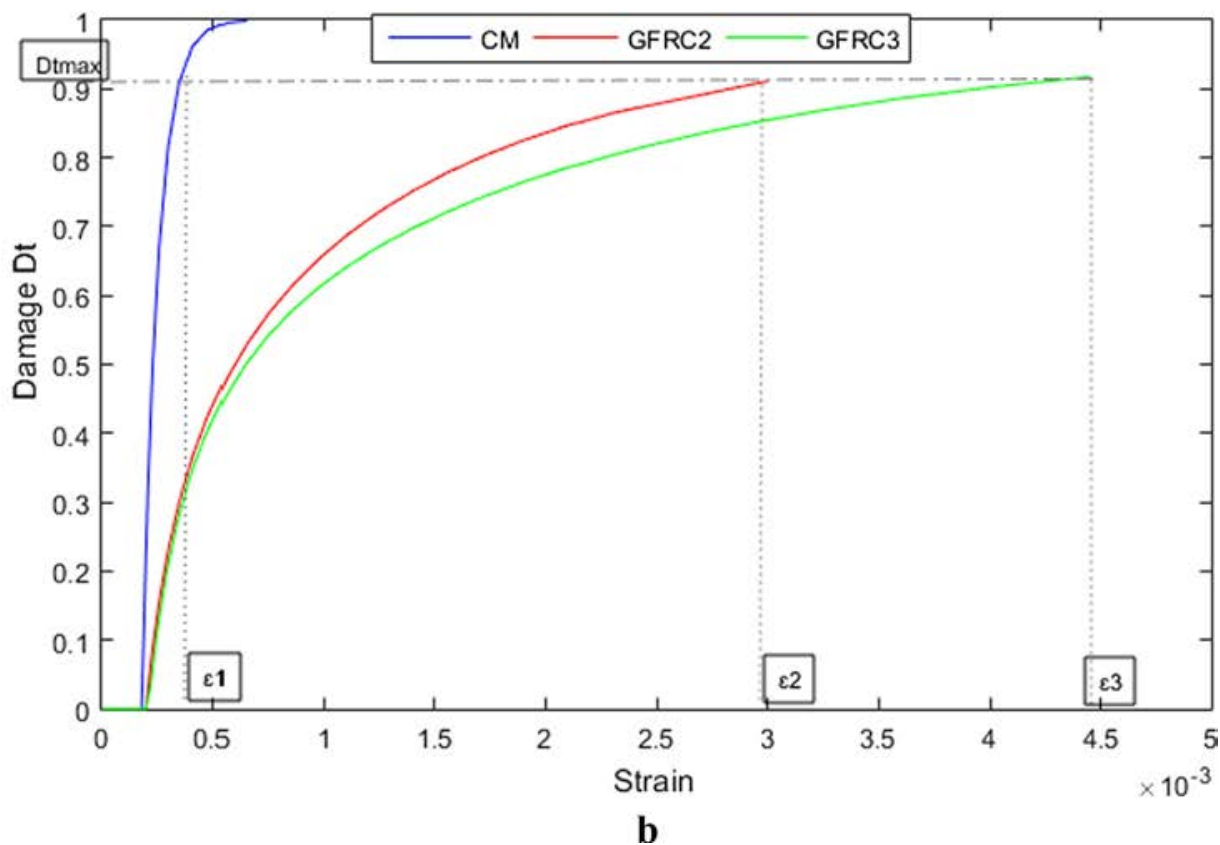

Fig. 14. a - Constitutive tensile behavior law. b - Evolution of Damage parameter.

Table 9

Comparison between experimental and analytical flexural proprieties.

\begin{tabular}{|c|c|c|c|c|c|c|}
\hline & \multicolumn{2}{|l|}{$\mathrm{CM}$} & \multicolumn{2}{|l|}{ GFRC2 } & \multicolumn{2}{|l|}{ GFRC3 } \\
\hline & Experimental & Analytical & Experimental & Analytical & Experimental & Analytical \\
\hline Maximum load $\mathrm{F}_{\max }(\mathrm{kN})$ & 9.8 & 9.88 & 13.63 & 13.19 & 15.86 & 16.7 \\
\hline Maximum deflection $\mathrm{d}_{\max }(\mathrm{mm})$ & 0.18 & 0.152 & 0.38 & 0.325 & 0.62 & 0.47 \\
\hline Ultimate deflection $\mathrm{d}_{\mathrm{u}}(\mathrm{mm})$ & 0.42 & 0.71 & 0.62 & 0.68 & 1 & 1.19 \\
\hline Maximum damage $\mathrm{D}_{\mathrm{tmax}}$ & - & 0.991 & - & 0.911 & - & 0.901 \\
\hline
\end{tabular}




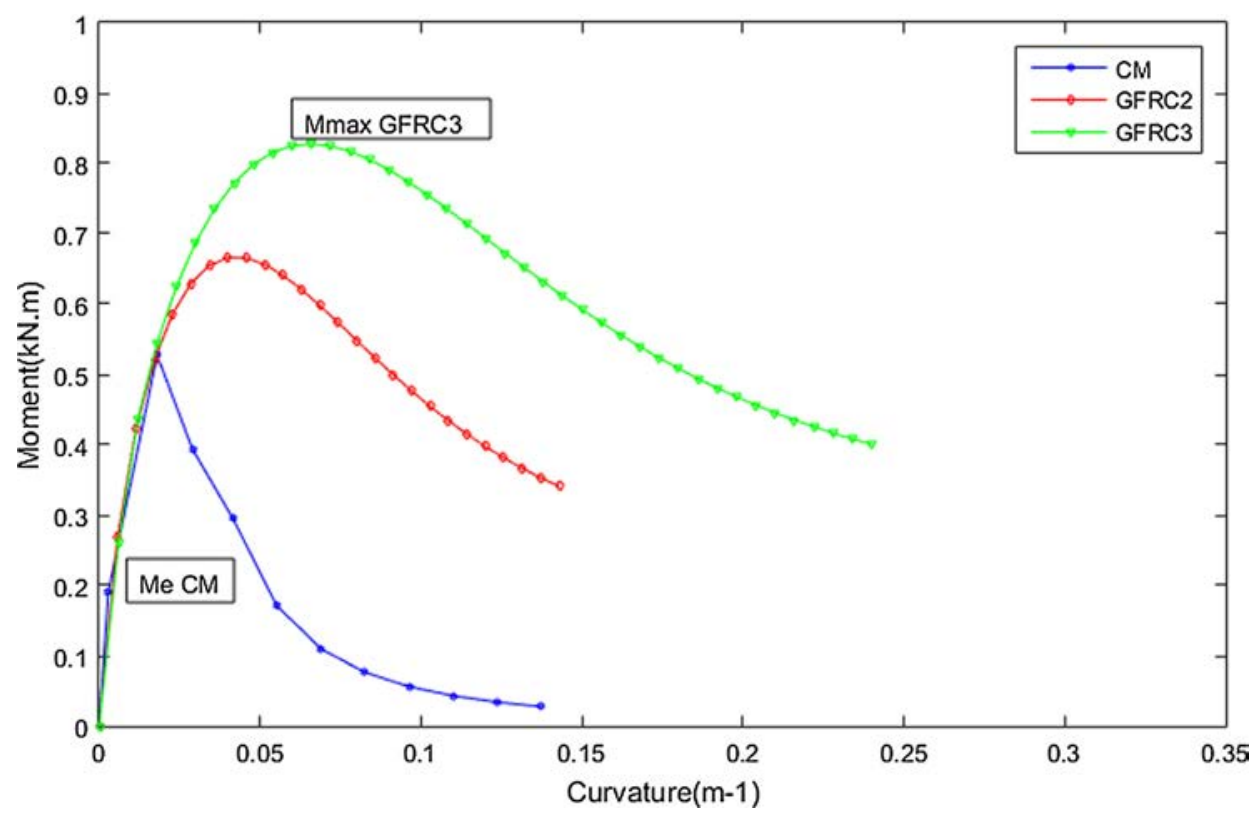

Fig. 15. Bending Moment -Curvature-relationship curves for tested beams.

and warping on structural behavior is important for low $\mathrm{L} / \mathrm{h}$ ratios. However, it became very close from $\mathrm{L} / \mathrm{h}=3$.

Fig. 12 shows that the deflection ratio (Timoshenko/Bernoulli) and (Levinson /Bernoulli) keep constant from $\mathrm{L} / \mathrm{h}=3$. The interpretation of these results assumes that the higher order theory can well describe the total deflection for short beams which have an aspect ratio range less than 3 . Hence, the classical solution is useful for a slander beams which have a span height ratio equal or more than 3, in this case, the shear effect and the warping can be neglected. In the next section, for our standard bending test $\mathrm{L} /$ $\mathrm{h}=3$ (NT 21.123), we will use the classical beam theory.

\section{Identification of model parameters from the experimental curves}

\subsection{Process of identification}

The proposed model described above is used to identify model parameters from the experimental results obtained in the first section by three-point bending tests (NT 21.123). In order to identify the damage tensile parameters of our model, an optimization algorithm is applied. Optimization seeks to find the values of model's parameters that minimize the gap between experimental and analytical loads. Assuming that the initial modulus of elasticity in compression and tensile are equal, the model requires the identification of three parameters which are the damage threshold $\varepsilon_{\mathrm{d} 0}$, the parameters $A_{t}$ and $B_{t}$ (Eq. (2)) which have an influence on the slope of the non-linear branch of the evolution of damage material response in tension. The objective function to optimize is defined in Eq. (10) as function of $\mathrm{N}$ experimental and analytical forces corresponding to fixed set of deflections values in the bending test. This process is followed by the least squares' method.

$\sum_{\mathrm{i}=1}^{\mathrm{N}}\left(\mathrm{F}_{\exp }{ }^{\mathrm{i}}-\mathrm{F}_{\mathrm{ana}}{ }^{\mathrm{i}}\left(\varepsilon_{\mathrm{d} 0}, \mathrm{~A}_{\mathrm{t}}, \mathrm{B}_{\mathrm{t}}\right)\right)^{2} \rightarrow \min$

\subsection{Identification of model parameters of GFRC}

The aim of this section is to validate the previous results of the proposed model which can able to identify the tensile parameters of the material by adjusting to the experimental curves. The parametric identification process is done for the mean experimental curves obtained for each micro-concrete without fibers CM, GFRC2 with $2 \%$ and GFRC3 with $3 \%$ having the same geometries of prismatic beams $70 \times 70 \times 280 \mathrm{~mm}$ (a span of $210 \mathrm{~mm}$ ). Table 8 summarizes the different tensile parameters before and after the adjustment process.

Fig. 13 shows the comparison of the load-displacement experimental results of mean curves obtained above (Fig. 6) and the analytical model after the adjustment process. In this Figure, it is clear that the experimental curves and the analytical Bernoulli curves show good agreement in the elastic phase. However, in the postpeak phase the analytical curves approximate the experimental curves with an error of $16.7 \%$ for CM, $5.1 \%$ for GFRC2 and $15 \%$ for GFRC3. Furthermore, the comparison of different beam theories solutions shows that the classical theory gives a good ability to describe the experimental results using prismatic beams with the ratio $\mathrm{L} / \mathrm{h}$ equal to 3 . Consequently, the classical beam theory is sufficient in the frame of the standard test NT 21.123 (NF P 18-407).

The tensile stress-strain constitutive relationship which is determined from Eqs. (1) and (2) and the experimental mechanical material's parameters already identified (Table 8) is illustrated in Fig. 14-a. Final failure is governed by the damage parameter $D_{t}$. It is noted that failure is observed for a $D_{\text {tmax }}>0.9$ for CM, GFRC2 and GFRC3 as is shown in Fig. 14-b and Table 9.

\section{Effect of slabs and beams thickness on ultimate bending moment capacity}

The aim of this section is to use the proposed flexural momentcurvature model for a parametric study of GFRC slabs and beams in bending and particularly in order to determine the ultimate bending moment capacity as a function of their thickness. By using the tensile parameters of the materiel which are already identified in the Section 4.2, Fig. 15 shows an example of the curvaturemoment curves obtained using the same mechanical proprieties and geometrical characteristics of tested CM, GFRC2 and GFRC3 rectangular beams.

Using this numerical tool developed, a parametric study is performed. As indicated in Fig. 16, the ultimate bending moment capac- 


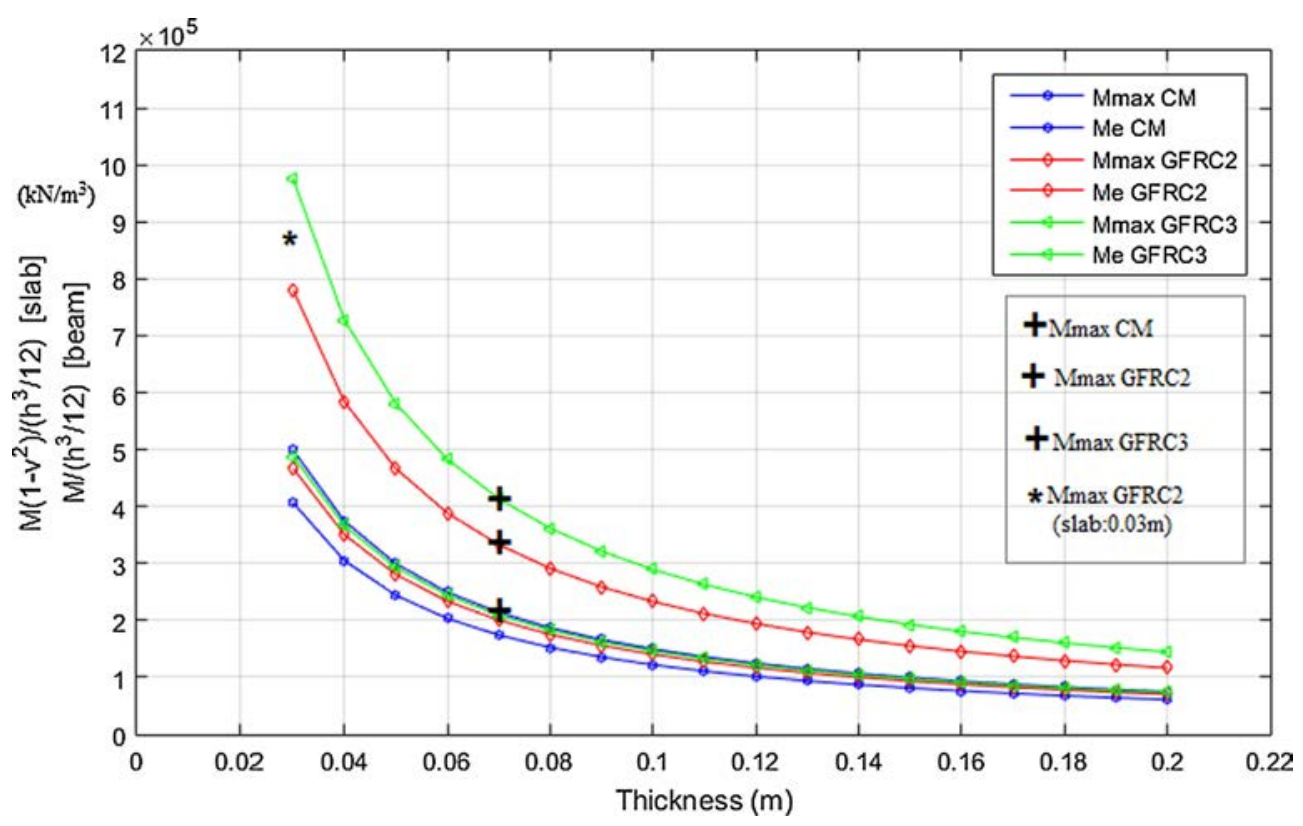

Fig. 16. Ultimate bending moment and elastic moment as function of slab and beam thickness $(v=0.2)$.

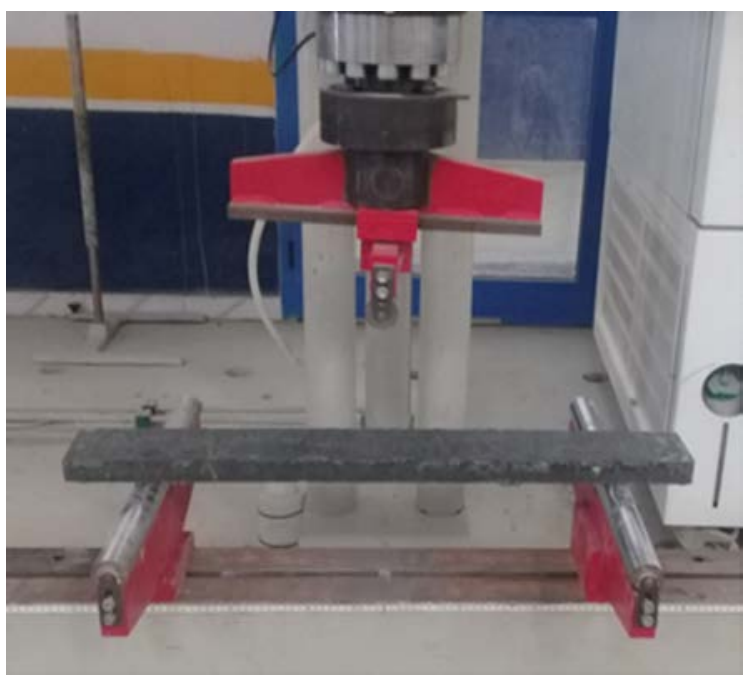

Fig. 17. Bending test set-up of the GFRC2 slab.

ity of a beam or a slab normalized respectively by the moment of inertia $\frac{b h^{3}}{12}$ for beams and $\frac{b h^{3}}{12\left(1-v^{2}\right)}$ for slabs as a function of their respectively height and thickness varying from $3 \mathrm{~cm}$ to $20 \mathrm{~cm}$.

In Fig. 16 are illustrated also experimental values of the previously tested beams and the ultimate bending moment capacity of a tested one-way GFRC2 slab under cylindrical bending and having a span of $0.6 \mathrm{~m}$ and a thickness of $0.03 \mathrm{~m}$ (Fig. 17).

This parametric study is useful for structural analysis of slabs using for example the limit analysis methods based on the yield line theory $[33,34]$. These methods are considered as a robust design tool for reinforced concrete slabs based on failure mechanisms at the ultimate limit state and need particularly the ultimate moment capacity.

\section{Conclusion}

For the pre-defined mixtures CM, GFRC2 and GFRC3, it can be concluded that:
- GFRC2 and GFRC3 are higher compressive and tensile strengths than $\mathrm{CM}$.

- The compressive strength of GFRC2 is slightly higher than GFRC3.

- An increase of flexural stiffness and ductility of micro-concrete due to addition of glass fibers is observed from the experimental load -vertical displacement curves.

- A simplified analytical damage model is developed. The moment-curvature constitutive flexural behavior is derived.

- Load-deflection is established by using different beams theories (Bernoulli, Timoshenko and Levinson beam theories). A torsional spring having a damage behavior is introduced in the midspan in order to model the observed experimentally failure mechanism at the post-peak phase bending response.

- It is shown that the classical beam theory is sufficient to estimate the behavior of short beams having a span to height equal to 3 according to NT 21-123.

- An identification algorithm is applied to determine the tensile parameters of the damage model of CM, GFRC2 and GFRC3 by adjusting the analytical load-deflection structural behavior to the experimental one.

- A parametric study is performed in order to deduce the ultimate bending moment capacity as a function of GFRC slabs and beams thickness. This study is useful for the limit analysis yield line theory.

\section{Declaration of Competing Interest}

The authors have no affiliation with any organization with a direct or indirect financial interest in the subject matter discussed in the manuscript.

\section{Acknowledgements}

The authors acknowledge the financial supports of TIE Tunisian Energy Industries Society for providing the materials.

\section{Appendix A}

1. Obtain an initial guess of curvature

$\chi_{0}=\chi_{\mathrm{e}}+\Delta \chi$, where $\chi_{\mathrm{e}}=2 \varepsilon_{\mathrm{d} 0} /$ his the elastic limit of curvature. 
2. Solve the Eq. (5) to determine the depth of the neutral axis $\bar{y}$. It will be solved using iterative process on $\bar{y}$ until the normal force $\mathrm{N}$ be equal to zero.

3. Compute the corresponding value of the bending moment $\mathrm{M}$ from Eq. (6).

4. Generate the curve moment -curvature relationship $\mathrm{M}-\chi$.

\section{References}

[1] A.J. Majumdar, R.W. Nurse, Building, glass fibre reinforced cement, Mater. Sci. Eng. 15 (1974) 107-127.

[2] A. Enfedaque, M.G. Alberti, J.C. Galvez, The influence of additions in the use of glass fiber reinforced cement as a construction material, Mater. Sci. Appl. 7 (02) (2016) 89.

[3] J.G. Ferreira, F.A. Branco, Structural application of GRC in telecommunication towers, Constr. Build. Mater. 21 (1) (2007) 19-28.

[4] J.P.J.G. Ferreira, F.A.B. Branco, The use of glass fiber-reinforced concrete as a structural material, Exp. Tech. 31 (3) (2007) 64-73.

[5] J.Á. López, P. Serna, J. Navarro-Gregori, E. Camacho, An inverse analysis method based on deflection to curvature transformation to determine the tensile properties of UHPFRC, Mater. Struct. 48 (11) (2015) 3703-3718.

[6] C. Soranakom, B. Mobasher, Correlation of tensile and flexural responses of strain softening and strain hardening cement composites, Cem. Concr. Compos. 30 (2008) 465-477.

[7] C. Soranakom, B. Mobasher, Closed-form moment-curvature expressions for homogenized fiber-reinforced concrete, ACI Mater. J. 104 (2008).

[8] F. Baby, B. Graybeal, P. Marchand, F. Tout le monde, Flexural tension test methods for determination of the tensile stress-strain response of ultra-high performance fibre reinforced concrete, VIII International Conference on Fracture Mechanics of Concrete and Concrete Structures, 2013.

[9] B. Mobasher, M. Bakhshi, C. Barsby, Back calculation of residual tensile strength of regular and high-performance fiber reinforced concrete from flexural tests, Constr. Build. Mater. 70 (2014) 243-253.

[10] S. Dobrusky, G. Chanvillard, Inverse analysis tailored for UHPFRC, J. Eng. Mech. 143 (9) (2017) 04017102.

[11] FISCHER, Gregor. Characterization of fiber-reinforced cement composites by their tensile stress-strain behavior and quantification of crack formation, in: Proceedings of BEFIB, (2004) pp. 20-22.

[12] M. Singh, A.H. Sheikh, M.M. Ali, P. Visintin, M.C. Griffith, Experimental and numerical study of the flexural behaviour of ultra-high performance fiber reinforced concrete beams, Constr. Build. Mater. 138 (2017) 12-25.

[13] Recommendations of RILEM TC 162-TDF: Test and design methods for steel fiber reinforced concrete: Bending test. Mater. Struct., 35 (2002), 579-582.

[14] AFGC (Association Française de Génie Civil) Ultra high performance fiberreinforced concrete Interim Recommendations, Paris, 2013.

[15] S. Qian, V.C. Li, Simplified inverse method for determining the tensile properties of strain hardening cementitious composites (SHCC), J. Adv. Concr. Technol. 6 (2) (2008) 353-363.

[16] A. Abrishambaf, J.A. Barros, V.M. Cunha, Relation between fiber distribution and post-cracking behaviour in steel fibre reinforced self-compacting concrete panels, Cem. Concr. Res. 51 (2013) 57-66.
[17] J. Mazars, G. Pijaudier-Cabot, Continuum damage theory-application to concrete, J. Eng. Mech. 115 (2) (1989) 345-365.

[18] P. Rossi, High performance multimodal fiber reinforced cement composites (HPMFRCC): the LCPC experience, Mater. J. 94 (6) (1997) 478-783.

[19] CEM-FIL ${ }^{\circledR} 62$ - OCV Reinforcements http://www.ocvreinforcements.com/ uploadedFiles/Reinforcement/CemFil/Doc/10010693_D_CemFil_62_product_ sheet_ww_Rev8_final.pdf. (2014), (Accessed 13 February 2018).

[20] A. Ellouze, M.B. Ouezdou, M.A. Karray, Experimental study of steel fiber concrete slabs part I: behavior under uniformly distributed loads, Int. J. Concr. Struct. Mater. 4 (2) (2010) 113-118.

[21] A.B. Kizilkanat, N. Kabay, V. Akyüncü, S. Chowdhury, A.H. Akça, Mechanical properties and fracture behavior of basalt and glass fiber reinforced concrete: an experimental study, Constr. Build. Mater. 100 (2015) 218-224.

[22] Y.M. Ghugal, S.B. Deshmukh, Performance of alkali-resistant glass fiber reinforced concrete, J. Reinf. Plast. Compos. 25 (6) (2006) 617-630.

[23] S.Y. Alam, P. Kotronis, A. Loukili, Crack propagation and size effect in concrete using a non-local damage model, Eng. Fract. Mech. 109 (2013) 246-261.

[24] G. Chanvillard, S. Rigaud, Complete characterization of tensile properties of Ductal UHPFRC according to the French recommendations, in: Proceedings of the 4th International RILEM workshop High Performance Fiber Reinforced Cementitious Composites, 2003, pp. 21-34.

[25] L. Dufort, S. Drapier, M. Grédiac, Closed-form solution for the cross-section warping in short beams under three-point bending, Compos. Struct. 52 (2) (2001) 233-246.

[26] G.R. Cowper, The shear coefficient in Timoshenko's beam theory, J. Appl. Mech. 33 (2) (1966) 335-340.

[27] I. Bitar, P. Kotronis, N. Benkemoun, S. Grange, A generalized Timoshenko beam with embedded rotation discontinuity, Finite Elem. Anal. Des. 150 (2018) 3450.

[28] M. Levinson, A new rectangular beam theory, J. Sound Vib. 74 (1981) 81-87.

[29] J.N. Reddy, C.M. Wang, G.T. Lim, K.H. Ng, Bending solutions of Levinson beams and plates in terms of the classical theories, Int. J. Solids Struct. 38 (26-27) (2001) 4701-4720.

[30] N. Challamel, Creep failure of a simply supported beam through a uniaxial continuum damage mechanics model, Acta Mech. 192 (2007) 213-234.

[31] N. Challamel, V. Picandet, G. Pijaudier-Cabot, From discrete to nonlocal continuum damage mechanics: analysis of a lattice system in bending using a continualized approach, Int. J. Damage Mech. 24 (7) (2015) 983-1012.

[32] F. Baby, B.A. Graybeal, P. Marchand, F. Toutlemonde, Identification of UHPFRC tensile behaviour: methodology based on bending tests. UHPFRC International Symposium on Ultra-High Performance Fibre-Reinforced, Concrete (2013) $10 \mathrm{p}$.

[33] K.W. Johansen, Yield-line Formulae for Slabs, CRC Press, 1972.

[34] H. Salehian, J.A. Barros, Prediction of the load carrying capacity of elevated steel fibre reinforced concrete slabs, Compos. Struct. 170 (2017) 169-191.

[35] S.J. Stephen, B. Raphael, R. Gettu, S. Jose, Determination of the tensile constitutive relations of fiber reinforced concrete using inverse analysis, Constr. Build. Mater. 195 (2019) 405-414.

[36] J.Á. López, P. Serna, J. Navarro-Gregori, H. Coll, A simplified five-point inverse analysis method to determine the tensile properties of UHPFRC from unnotched four-point bending tests, Compos. B Eng. 91 (2016) 189-204.

[37] Graybeal, B.A., Baby F. (2019). Tension Testing of Ultra -High -Performance Concrete Technical Report, No.FHWA-HRT-17-053 UB LICATION NO. FHWAHRT-17-053. 